\title{
Evaluación de competencias y objetivos formativos en la transición de la Estrategia Publicitaria y Rela- cional al Espacio Europeo Educación Superior
}

\author{
Concepción Campillo Alhama \\ Universidad de Alicante \\ concepcion.campillo@ua.es
}

\begin{abstract}
Resumen
La investigación evaluativa nos permite reorientar el proceso didáctico de los estudiantes universitarios. A través de este estudio se evalúa la adquisición de competencias, habilidades y destrezas vinculadas a la Estrategia Publicitaria y de Relaciones Públicas en los estudiantes del Grado de Publicidad y RR.PP. de la Universidad de Alicante, durante el curso académico 2012-2013. Los resultados de este estudio nos muestran la orientación futura que debemos otorgar a este proceso de enseñanza-aprendizaje, reforzando los objetivos formativos menos consolidados.
\end{abstract}

Palabras clave: Publicidad; Relaciones Públicas; Estrategia; EEES; Evaluación.

Evaluation of competencies and training objectives in the transition from Relational Advertising Strategy to the European Higher Education

\begin{abstract}
Evaluative research allows us to reorient the learning process of university students. Through this study evaluates the acquisition of skills, abilities and skills associated to the Strategy in Advertising and Public Relations students in Advertising and Public Relations degree from the University of Alicante, in the academic year 2012-2013. The results of this study show the future direction we should give this teaching-learning process, reinforcing the training goals less consolidated.
\end{abstract}

Keywords: Advertising; Public Relations; Strategy; European Higher Education Area; Evaluation

\section{Referencia normalizada:}

Campillo Alhma. C. (2013) Evaluación de competencias y objetivos formativos en la transición de la Estrategia Publicitaria y Relacional al Espacio Europeo de Educación Superior. Historia y Comunicación Social Vol. 18 Nºspecial Octubre. Págs. 133-146

Sumario: 1.Introducción. 2. La Estrategia Publicitaria-Relacional en su transición al EEES. 3. Metodología. 4. Resultados. 5. Conclusiones. 6. Referencias bibliográficas

\section{Introducción}

En el actual contexto de acuciante crisis económica la idoneidad en la adquisición de competencias (cognitivas, procedimentales y actitudinales) a través de los actuales planes de estudio de educación superior, junto a las habilidades y destrezas de los 
perfiles profesionales, resultan variables fundamentales para establecer un vínculo sólido y permanente entre la Universidad y el mercado laboral.

Para las instituciones universitarias, esta situación implica un proceso de reflexión y transformación de las estructuras y contenidos en su oferta de estudios. En este proceso de reforma van a desempeñar un papel fundamental no sólo los objetivos establecidos por la propia comunidad académica sino también los perfiles académicos y profesionales que exige la sociedad (González y Wagenaar, 2003) para poder absorber el flujo de estudiantes graduados.

Todo este proceso, en el que nos encontramos inmersos, obedece a la previsión que ya establecía el Título XIII de la Ley Orgánica 6/2001, de 21 de diciembre, de Universidades. Como consecuencia de esta coyuntura, el Ministerio de Educación, Ciencia y Deporte elaboró, en febrero del 2003, un documento-marco que contiene un conjunto de propuestas orientadas, por un lado, a servir de punto de partida para la reflexión que debe producirse en las universidades y administraciones educativas; y por otro, a posibilitar los acuerdos necesarios sobre los aspectos fundamentales del proceso de integración al EEES

\section{La estrategia publicitaria-relacional en su transición al eees}

El Espacio Europeo de Enseñanza Superior representa un nuevo escenario en el contexto universitario en el que las propuestas formativas se caracterizan por una mayor transparencia y comparabilidad.

Tal y como afirman Tardif (2004) o Zabalza (2004), el diseño de los planes de estudio, las metodologías y los programas académicos se conciben, en consecuencia, a partir de la referencia básica del proceso de aprendizaje que van a desarrollar los estudiantes y no sólo por la intervención docente.

Las nuevas propuestas formativas se estructuran en créditos europeos (ECTs) como el cómputo de trabajo realizado por el alumno en este proceso de forma global. Por otra parte, el denominado suplemento europeo al título va a ayudar a un reconocimiento de la formación adquirida, mucho más sencillo y equitativo por parte de otras universidades y organismos europeos; en consecuencia, la estructura de las enseñanzas y los niveles de las titulaciones que recibirán los alumnos al finalizar sus estudios serán mucho más homogéneos con los títulos y enseñanzas de los países de la Unión Europea. Con ello se pretende favorecer la movilidad y la integración de los estudiantes en el mercado laboral.

Una de las cuestiones más complejas, desde el punto de vista académico, es la necesidad manifiesta de diseñar una metodología que permita evaluar la adquisición de competencias de los estudiantes durante su periodo formativo, y promover así la certificación de las competencias dentro del curriculum vitae (Fanjul y González, 2010). En este sentido, se propone una investigación que supone, como ejercicio de reflexión docente, un proceso de evaluación a desarrollar en tres fases: en primer 
término, estableceremos las competencias necesarias para alcanzar todos los objetivos específicos asignados a la asignatura "Estrategia de la Publicidad y de las Relaciones Públicas" del nuevo título de Grado en Publicidad y Relaciones Públicas en la Universidad de Alicante; en segundo lugar, identificaremos los objetivos que van a estar vinculados a cada una de las competencias (tabla 1) y, por último, analizaremos si los resultados obtenidos constatan la eficacia de la propuesta docente de dicha asignatura obligatoria, así como qué aspectos en concreto sería pertinente reforzar en experiencias futuras de enseñanza-aprendizaje para esta materia en el nuevo Grado universitario.

\section{Metodología}

Nos planteamos, en consecuencia, como objetivo general de esta investigación, analizar qué objetivos específicos y competencias básicas han sido alcanzados de forma notable, durante el curso académico 2012-2013, por parte de los estudiantes que han cursado, en la Universidad de Alicante, la asignatura Estrategia de la Publicidad y de las Relaciones Públicas, y tomar como referencia dichos resultados en futuras experiencias docentes en la institución educativa. A partir de dicho análisis, podremos reforzar aquellos objetivos que no se han conseguido de forma suficiente.

Para ello nos planteamos desarrollar una investigación exploratoria, en la que se va a aplicar una herramienta ad hoc de diagnóstico y evaluación, Como método de análisis se va a utilizar un cuestionario estructurado en 18 preguntas, basado en la técnica aditiva de Likert, graduado a partir de la intensidad con que se presentan diferentes factores para medir la actitud de los sujetos. Se solicita a los estudiantes, entre otras cuestiones, que autovaloren su grado de adquisición de competencias cognitivas y procedimentales sobre los fundamentos de la dirección estratégica aplicados a la comunicación publicitaria y relacional, el conocimiento del diseño y desarrollo de las estrategias de comunicación persuasiva, el estudio de los procesos de comunicación y su evaluación, o la capacidad de análisis, síntesis y de juicio crítico que permite tomar decisiones estratégicas respecto a la conceptualización de los mensajes de comunicación.

Nuestro universo está formado por 49 estudiantes matriculados en esta asignatura durante el curso académico 2012-2013. Según criterios estadísticos de inferencia probabilística, se aplica un nivel de confianza del $95,5 \%$ y un margen de error del $3 \%$., resultando una muestra mínima representativa de 36 sujetos. 
Tabla 1. Competencias específicas y objetivos de aprendizaje de la asignatura Estrategia de la Publicidad y las RR.PP. (UA)

\begin{tabular}{|c|c|}
\hline Competencia & Objetivo formativo \\
\hline $\begin{array}{l}\text { C.1. Desarrollo de } \\
\text { los fundamentos } \\
\text { conceptuales } \\
\text { de la dirección } \\
\text { estratégica aplicados } \\
\text { a la comunicación } \\
\text { publicitaria }\end{array}$ & $\begin{array}{l}\text { O.1.) Conocer los orígenes históricos y la evolución de la disciplina. } \\
\text { O.2.) Profundizar en la conceptualización y reformulación de la Nueva } \\
\text { Teoría Estratégica. } \\
\text { O.3.) Analizar y comprender la naturaleza de los procesos estratégicos. } \\
\text { O.4.) Identificar y aplicar las fases de la actuación estratégica. } \\
\text { O.5.) Identificar las diferentes variables intervinientes en el proceso } \\
\text { estratégico de las organizaciones. } \\
\text { O.6.) Ser capaz de analizar objetivamente la realidad, a fin de extraer } \\
\text { consideraciones válidas. } \\
\text { O.7.) Distinguir los siguientes conceptos: objetivo, estrategia, táctica y } \\
\text { planificación. } \\
\text { O.8.) Identificar los fundamentos de la estrategia de comunicación } \\
\text { publicitaria. } \\
\text { O.9.) Identificar los fundamentos de la estrategia de relaciones públicas. } \\
\text { O.10.) Elaborar modelos que puedan ser implementados en procesos } \\
\text { estratégicos. } \\
\text { O.11.) Interpretar modelos estratégicos aplicados a diferentes } \\
\text { situaciones en el contexto de las organizaciones. } \\
\text { O.12.) Distinguir las orientaciones del pensamiento estratégico } \\
\text { aplicado al marketing, a la comunicación publicitaria y a las relaciones } \\
\text { públicas }\end{array}$ \\
\hline $\begin{array}{l}\text { C.2. Conocimiento } \\
\text { del diseño y } \\
\text { desarrollo de las } \\
\text { estrategias de } \\
\text { comunicación } \\
\text { persuasiva }\end{array}$ & $\begin{array}{l}\text { O.13.) Identificar las variables y las operaciones básicas existentes en } \\
\text { cualquier proceso estratégico aplicado a la comunicación integral. } \\
\text { O.14.) Conocer el proceso de desarrollo de la estrategia publicitaria. } \\
\text { O.15.) Conocer el proceso de desarrollo de la estrategia relacional. } \\
\text { O.16.) Ser capaz de formular la estrategia de comunicación, a partir de } \\
\text { objetivos prestablecidos. } \\
\text { O.17.) Ser capaz de distinguir e interpretar diferentes tipos de } \\
\text { estrategias de comunicación publicitaria y de relaciones públicas }\end{array}$ \\
\hline $\begin{array}{l}\text { C.3. Conocimiento } \\
\text { y estudio de } \\
\text { los procesos de } \\
\text { comunicación y sus } \\
\text { técnicas específicas: } \\
\text { posicionamiento, } \\
\text { segmentación, } \\
\text { procedimientos de } \\
\text { análisis y medición } \\
\text { de la eficacia }\end{array}$ & $\begin{array}{l}\text { O.18.) Aplicar técnicas específicas de un proceso de comunicación. } \\
\text { O.19.) Conocer las aportaciones del «posicionamiento» al marketing y } \\
\text { a la publicidad. } \\
\text { O.20.) Profundizar en las características que determinan el } \\
\text { posicionamiento. } \\
\text { O.21.) Conocer las herramientas básicas para realizar segmentaciones y } \\
\text { determinar el posicionamiento. } \\
\text { O.22.) Programar acciones concretas de comunicación, especialmente } \\
\text { publicitarias y de las relaciones públicas. } \\
\text { O.23.) Diseñar e implementar mecanismos útiles para la medición de la } \\
\text { eficacia de los resultados }\end{array}$ \\
\hline
\end{tabular}




\begin{tabular}{|c|c|}
\hline Competencia & Objetivo formativo \\
\hline $\begin{array}{l}\text { C.4. Capacidad de } \\
\text { asesorar al anunciante } \\
\text { desde el análisis e } \\
\text { interpretación de } \\
\text { sus necesidades } \\
\text { de comunicación } \\
\text { publicitaria y de las } \\
\text { relaciones públicas }\end{array}$ & $\begin{array}{l}\text { O.24.) Adquirir conciencia de las especificidades propias del ejercicio } \\
\text { de la comunicación publicitaria y de las relaciones públicas, según el } \\
\text { perfil y las necesidades propias del anunciante. } \\
\text { O.25.) Profundizar en el rol del Account Planner y sus funciones. } \\
\text { O.26.) Desarrollar y organizar la información del anunciante referida al } \\
\text { consumidor, al producto y al mercado. } \\
\text { O.27.) Estructurar la información del anunciante para obtener un } \\
\text { conjunto coherente de actuación. } \\
\text { O.28.) Ser capaz de diseñar diferentes tipos de briefing e interpretar de } \\
\text { forma estratégica el contrabriefing. } \\
\text { O.29.) Valorar la estrategia publicitaria y de relaciones públicas dentro } \\
\text { de la estrategia de marketing relacional. } \\
\text { O.30.) Centrar los objetivos de comunicación. } \\
\text { Identificar y definir el sector de audiencia a quien se dirige la } \\
\text { comunicación. } \\
\text { O.31.) Formular la estrategia de comunicación. }\end{array}$ \\
\hline $\begin{array}{l}\text { C.5. Capacidad para } \\
\text { la toma de decisiones } \\
\text { estratégicas }\end{array}$ & $\begin{array}{l}\text { O.32.) Ser capaz de evaluar situaciones desde una perspectiva } \\
\text { estratégica. } \\
\text { O.33.) Aprender a formular objetivos a corto, medio y largo plazo. } \\
\text { O.34.) Demostrar habilidad par a elegir entre diferentes alternativas de } \\
\text { acción. }\end{array}$ \\
\hline $\begin{array}{l}\text { C.6. Capacidad de } \\
\text { análisis, de síntesis y } \\
\text { de juicio crítico que } \\
\text { le ayude a la } \\
\text { conceptualización de } \\
\text { los mensajes } \\
\text { publicitarios y de las } \\
\text { relaciones públicas. }\end{array}$ & $\begin{array}{l}\text { O.35.) Diseñar objetivos de comunicación publicitaria y de relaciones } \\
\text { públicas. } \\
\text { O.36.) Establecer la promesa comunicativa, key focus y generar } \\
\text { insights. } \\
\text { O.37.) Clasificar ventajas del producto y(o) servicio, así como los } \\
\text { beneficios más relevantes para la acción comunicativa. } \\
\text { O.38.) Diseñar instrucciones para la creación del mensaje. } \\
\text { O.39.) Seleccionar el eje de comunicación }\end{array}$ \\
\hline $\begin{array}{l}\text { C.7. Habilidad } \\
\text { para detectar } \\
\text { oportunidades del } \\
\text { mercado. }\end{array}$ & $\begin{array}{l}\text { O.40.) Comprender la evolución y las expectativas del mercado } \\
\text { y entorno social, producto/servicio y de los receptores de la } \\
\text { comunicación. } \\
\text { O.41.) Analizar las características de los productos y (o) servicios. } \\
\text { O.42.) Identificar, distinguir y reconocer tendencias emergentes. }\end{array}$ \\
\hline
\end{tabular}

Fuente: Memoria de Grado para el título de Publicidad y Relaciones Públicas de la Universidad de Alicante (2010). Elaboración propia.

Las competencias señaladas en la tabla anterior, representan, en este sentido, un saber hacer complejo, que es el resultado de la integración, movilización y adecuación de capacidades, habilidades y conocimientos en el ámbito formativo objeto de la investigación, utilizados eficazmente en situaciones que presentan un carácter común, 
tal y como apunta Lasnier (2000). Los participantes en la investigación respondieron de forma individual y voluntaria al cuestionario del estudio.

\section{Resultados}

Los resultados obtenidos nos permiten constatar el grado de consecución de los objetivos formativos señalados en la tabla anterior y, en consecuencia, la adquisición de competencias cognitivas, procedimentales y actitudinales asignadas a la materia "Estrategia de la Publicidad y de las Relaciones Públicas", a partir de valores graduales: siendo el mayor valor totalmente de acuerdo y el menor, totalmente en desacuerdo.

Gráfico 1. Adquisición de conocimientos suficientes sobre los orígenes históricos y la evolución de la disciplina

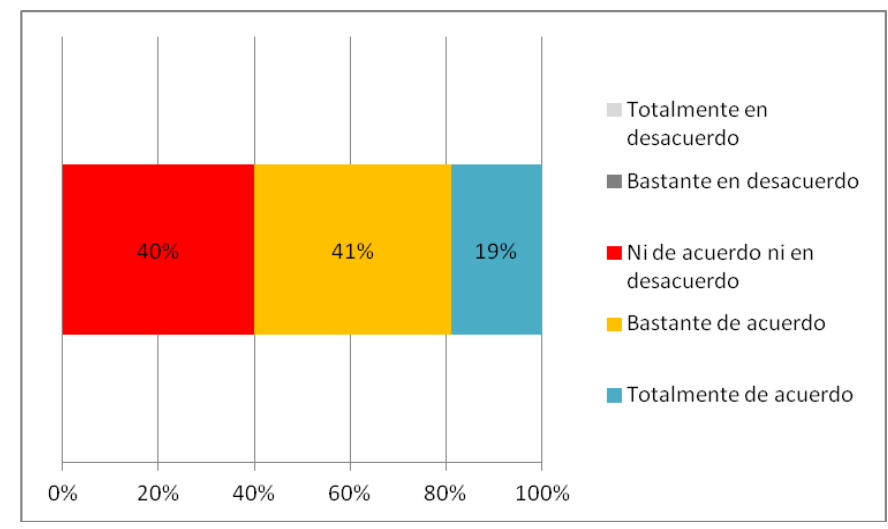

Gráfico 2. Adquisición de conocimientos suficientes sobre la conceptualización y reformulación de la Nueva Teoría Estratégica

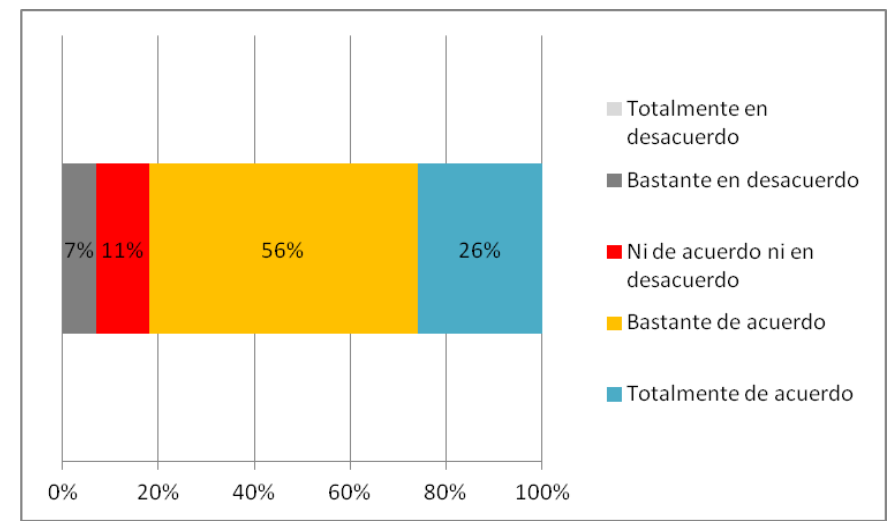


Gráfico 3. Capacidad para analizar y comprender la naturaleza de los procesos estratégicos

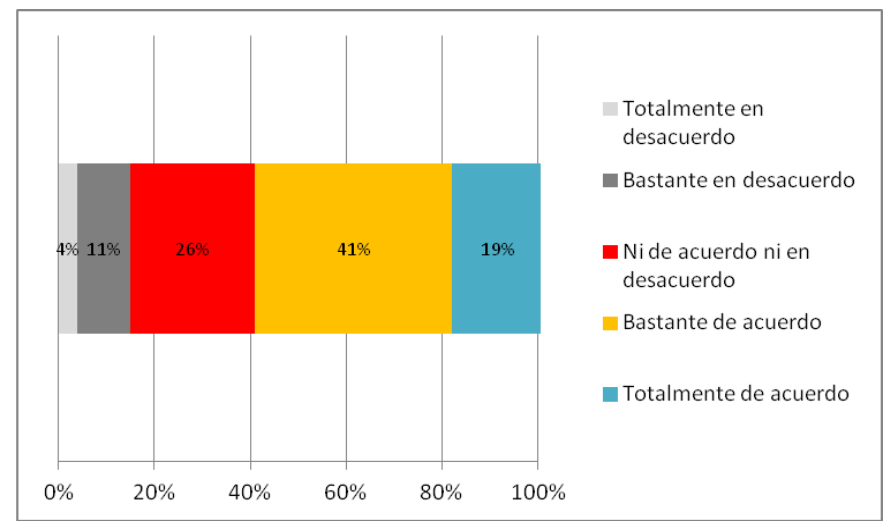

Gráfico 4. Capacidad para identificar y aplicar las fases de la actuación estratégica

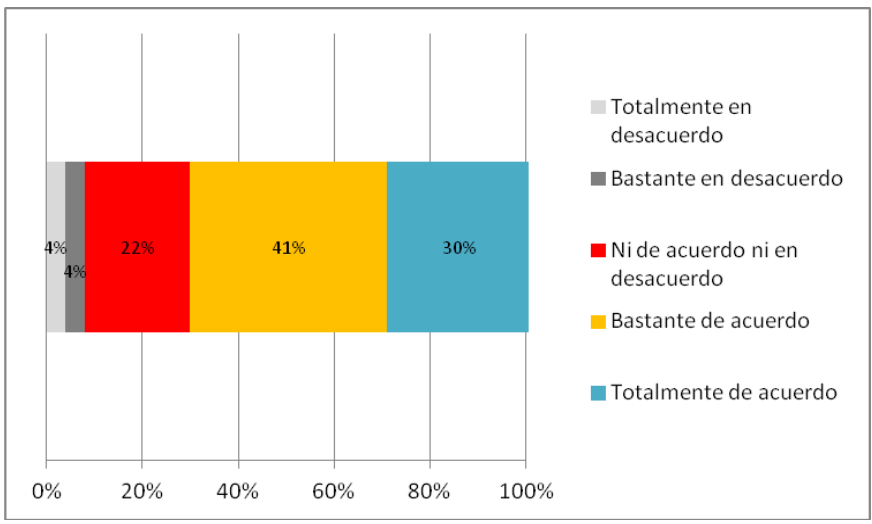

Gráfico 5. Capacidad para identificar las diferentes variables intervinientes en el proceso estratégico de las organizaciones

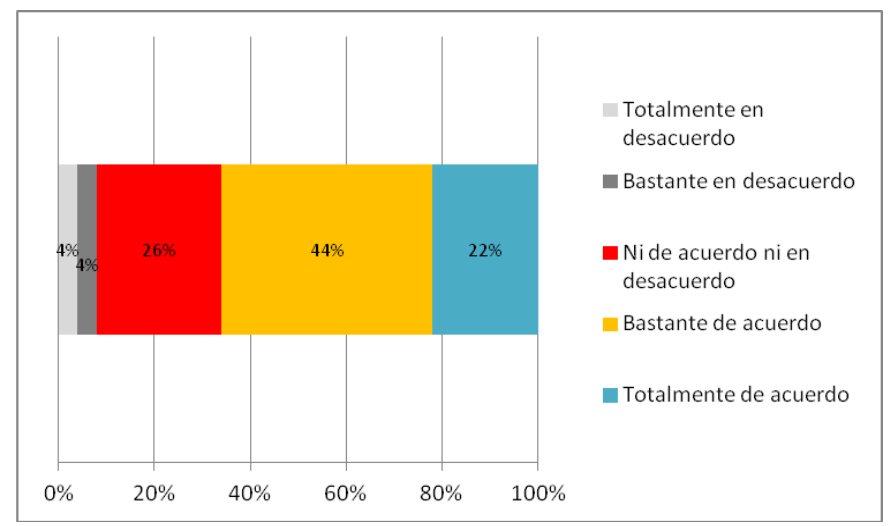


Gráfico 6. Capacidad de analizar objetivamente la realidad, a fin de extraer consideraciones válidas para el proceso estratégico

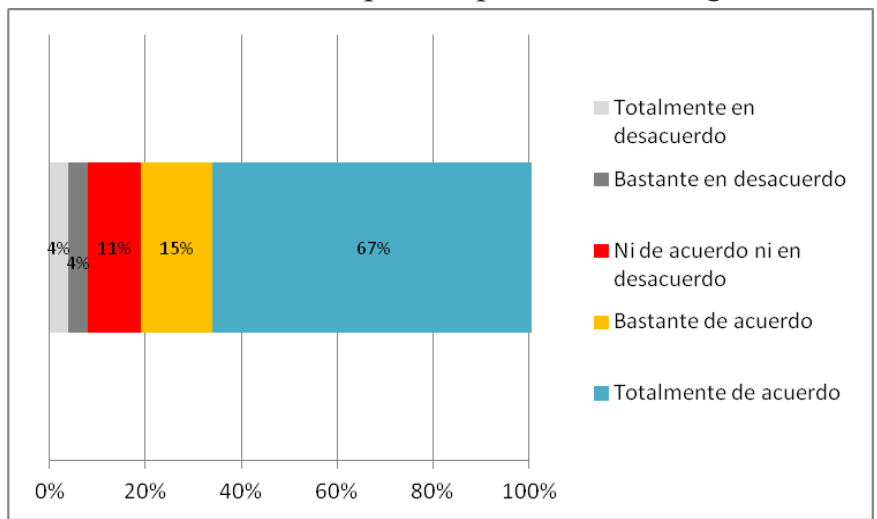

Gráfico 7. Capacidad de distinguir los siguientes conceptos: objetivo, estrategia, táctica y planificación

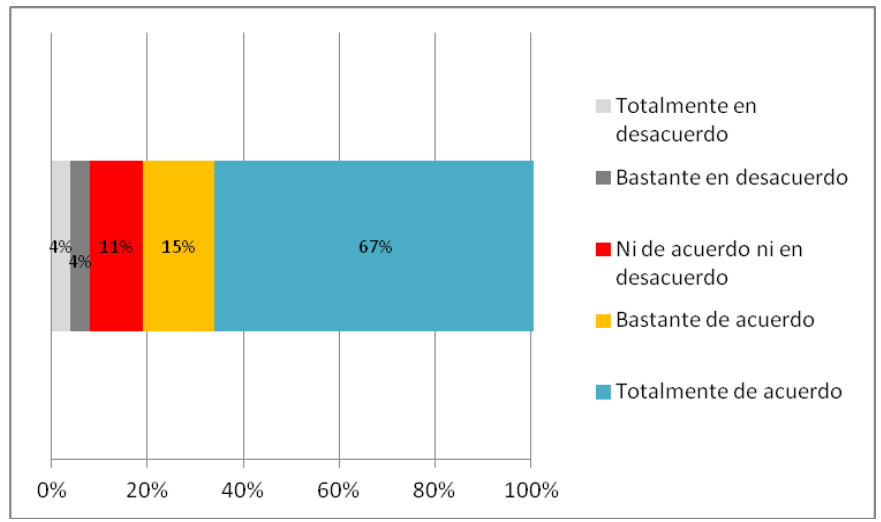

Gráfico 8. Capacidad para identificar los fundamentos de la estrategia de la comunicación publicitaria

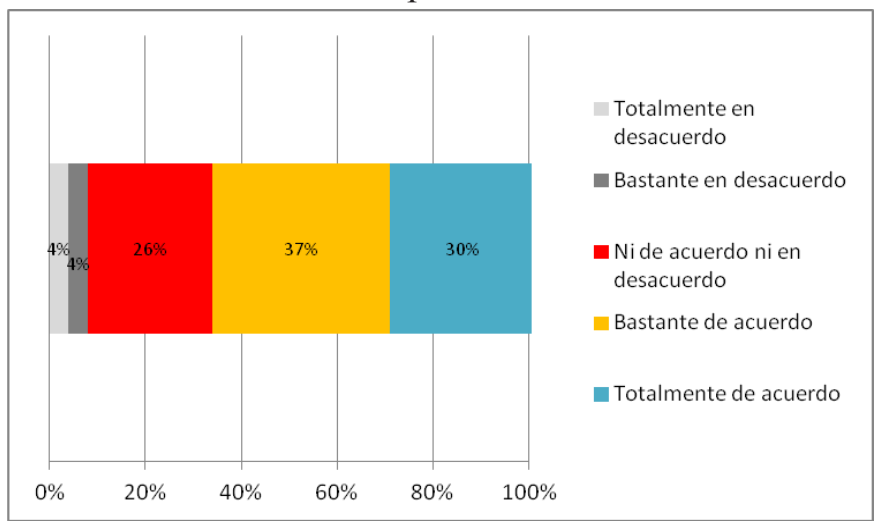


Gráfico 9. Capacidad para identificar los fundamentos de las relaciones públicas

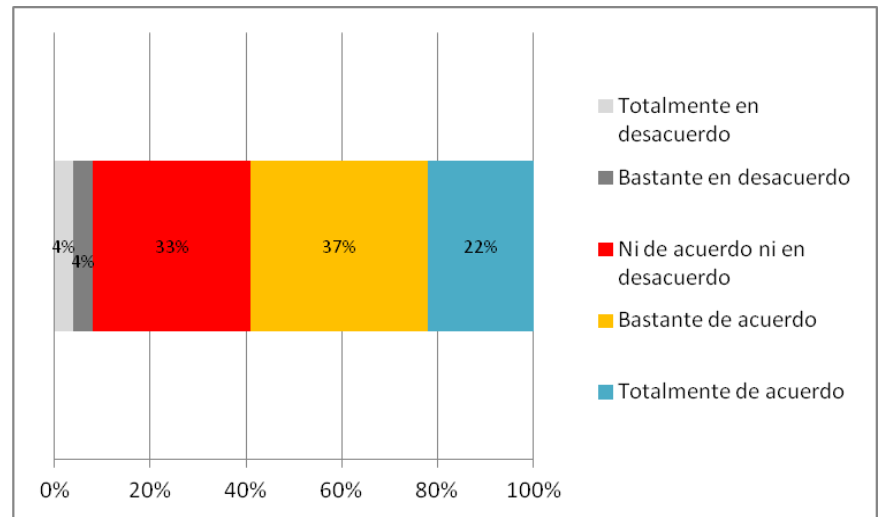

Gráfico 10. Capacidad para elaborar modelos para desarrollar procesos estratégicos

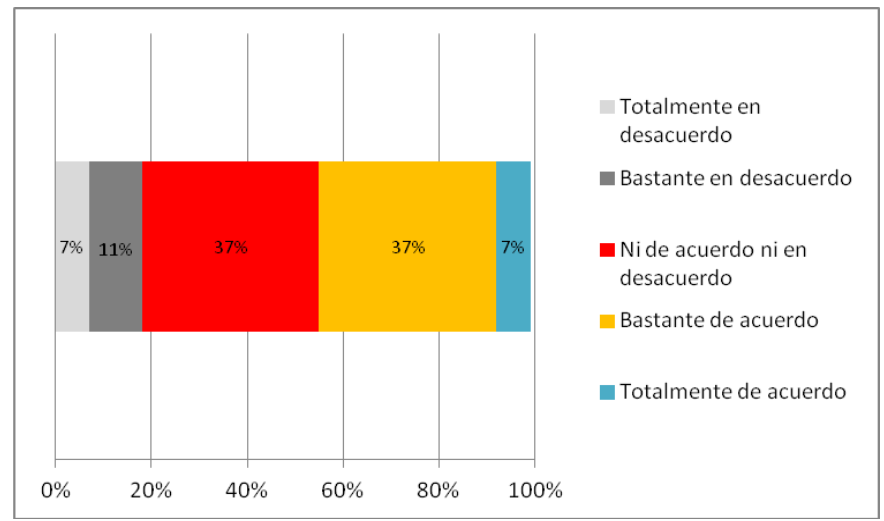

Gráfico 11. Capacidad para interpretar diferentes tipos de estrategias de comunicación publicitaria y de relaciones públicas

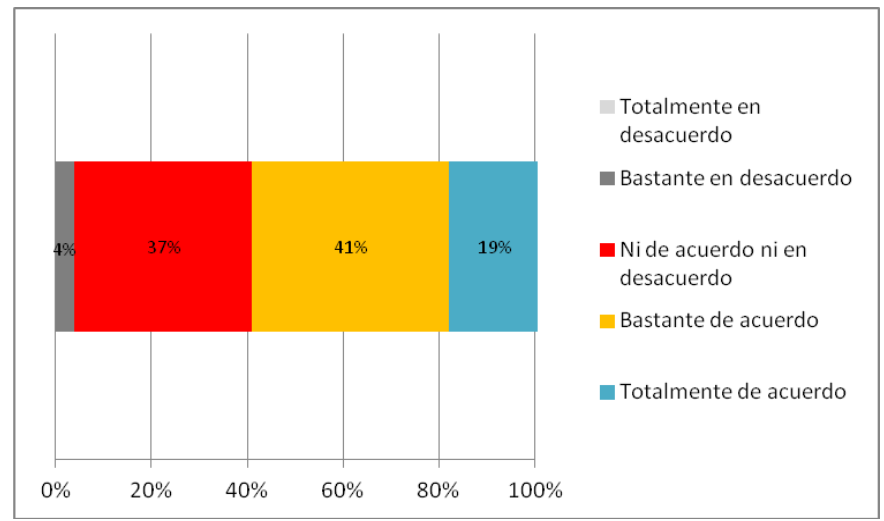


Gráfico 12. Adquisición de conocimientos suficientes sobre el posicionamiento al servicio del marketing y de la publicidad

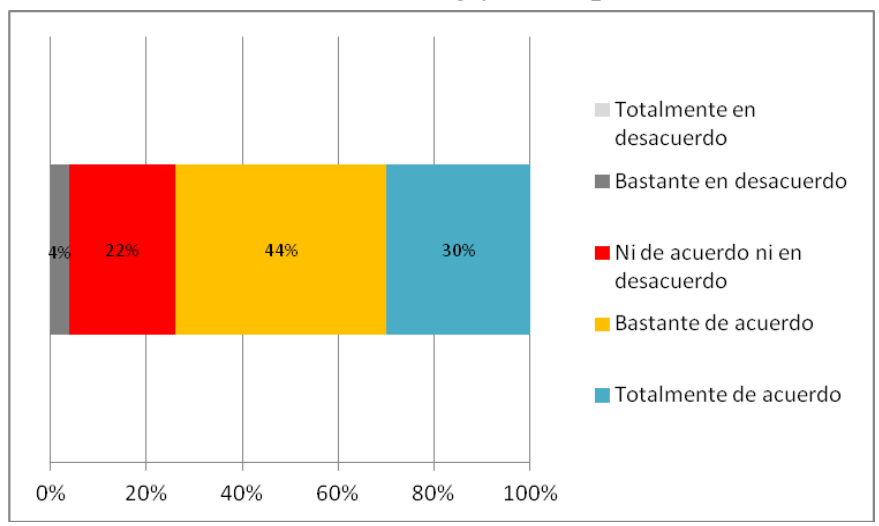

Gráfico 13. Capacidad para diseñar distintos tipos de briefing e intepretar de forma estratégica el contrabriefing

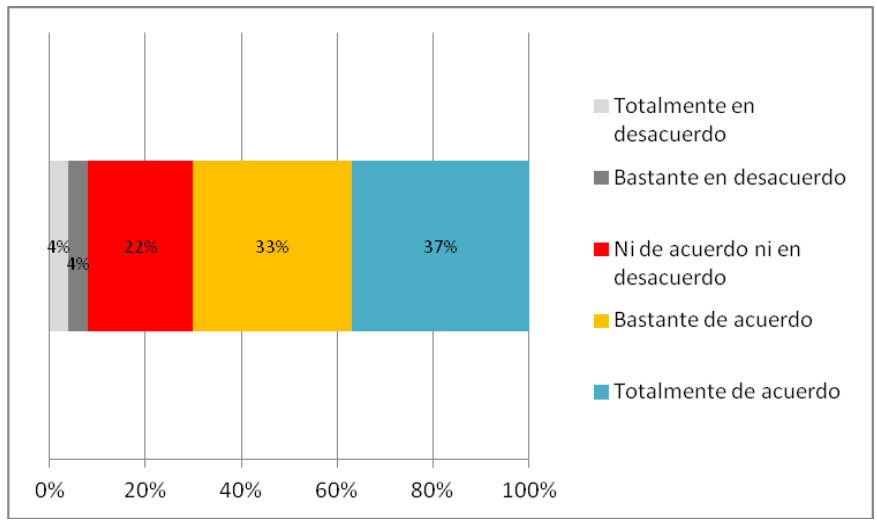

Gráfico 14. Capacidad para identificar y definir los objetivos de comunicación, la audiencia y formular la estrategia de comunicación

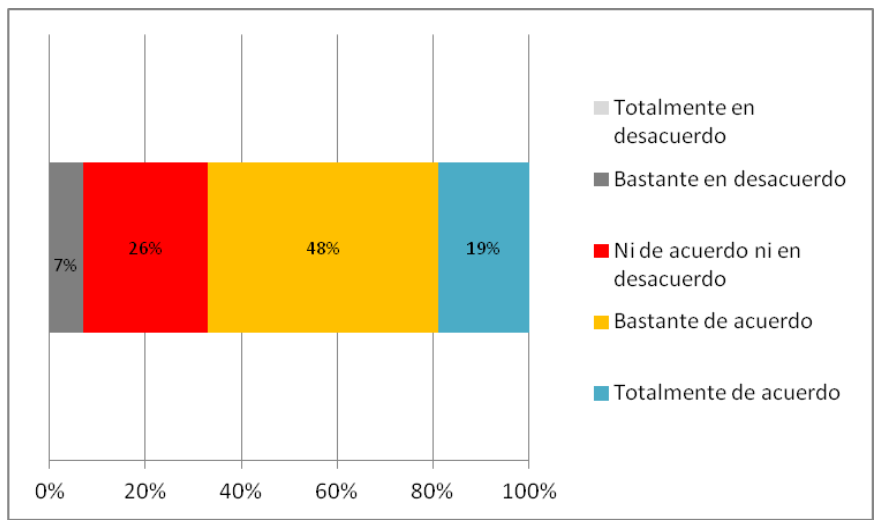


Gráfico 15. Capacidad para establecer la promesa comunicativa, key focus y generar insights; clasificar las ventajas del producto/servicio

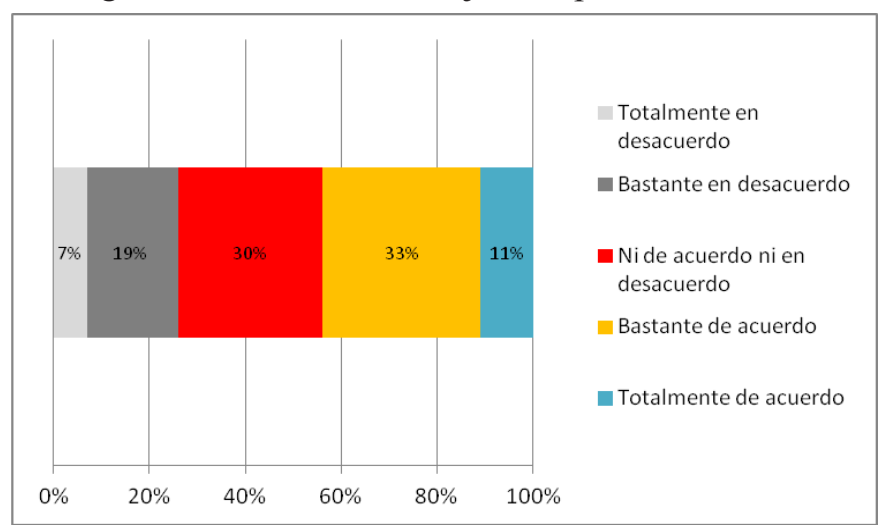

Gráfico 16. Capacidad para seleccionar el eje de comunicación y diseñar instrucciones para la creación del mensaje

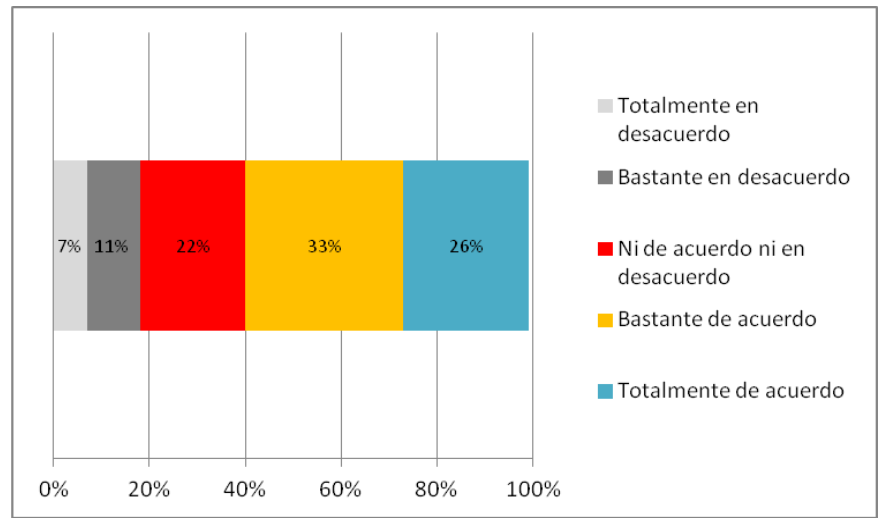

Gráfico 17. Capacidad para comprender la evolución y expectativas del mercado y entorno social, del producto/servicio y de los receptores de la comunicación. Identificación de tendencias emergentes

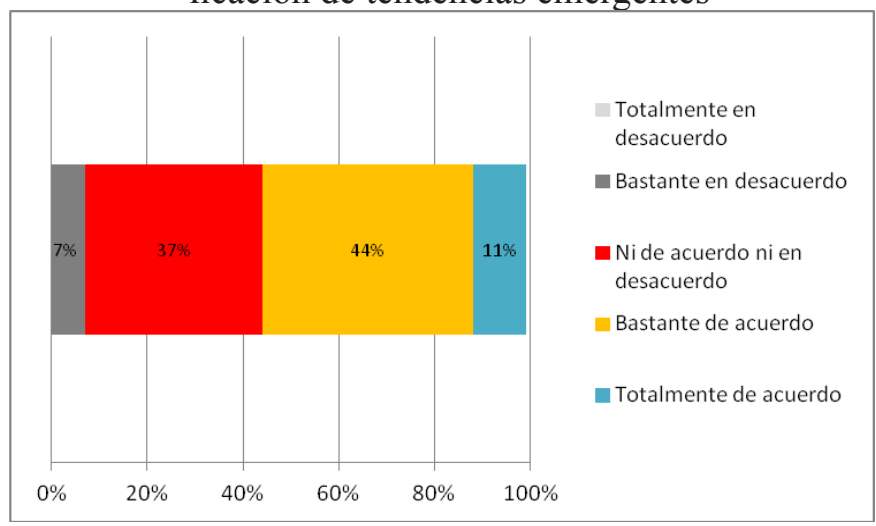


Gráfico 18. Adquisición de destrezas suficientes para diseñar e implementar mecanismos útiles para la medición de la eficacia de los resultados

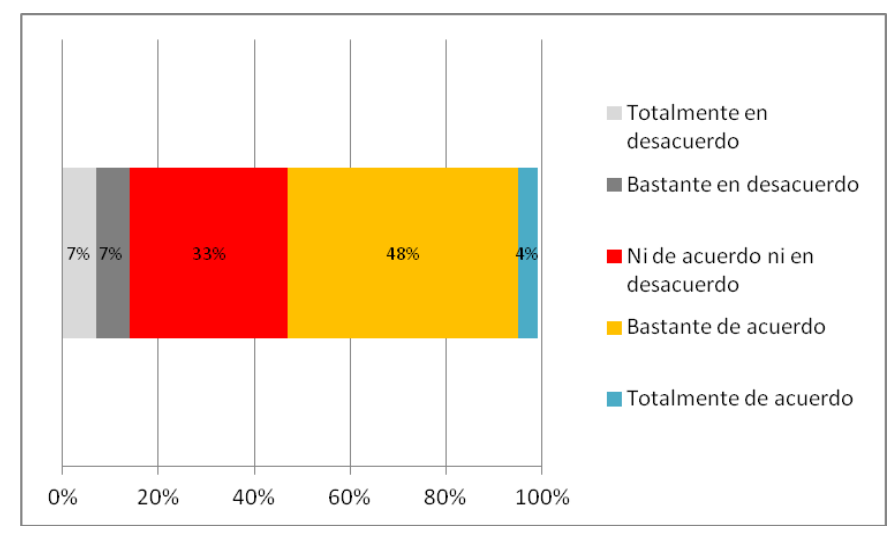

\section{Conclusiones}

El Espacio Europeo de Educación Superior supone una nueva forma de interacción didáctica de los profesores universitarios con los estudiantes. Este cambio de paradigma va a obligar a los profesionales de la enseñanza universitaria a adoptar todo tipo de medidas, conducentes a adaptarse a esta nueva realidad. Entre ellas, la aplicación de diferentes metodologías didácticas y recursos que garanticen el éxito en la transferencia de contenidos cognitivos, procedimentales y actitudinales.

A partir de esta investigación se establecen recomendaciones de diversa índole, para avanzar en la calidad de la docencia. Una de las cuestiones apuntadas por los alumnos se refiere a la necesidad de reforzar su capacidad para elaborar modelos estratégicos de gestión en comunicación publicitaria y relacional (gráfico 10), así como la capacidad para establecer la promesa comunicativa, el key focus, generar insights, o clasificar las ventajas del producto/servicio (gráfico 15): de hecho, sólo el $44 \%$ de los alumnos encuestados están totalmente de acuerdo o bastante de acuerdo cuando consideran que han adquirido ambas competencias formativas. Por tanto, convendría reforzar los contenidos y metodología docente asignada al proceso didáctico relativo a estos aspectos. El resto de competencias cognitivas, procedimentales y actitudinales se presentan como suficientemente adquiridas, en el $52 \%$ en el caso de la adquisición de destrezas para implementar mecanismos útiles para la medición de la eficacia de los resultados (gráfico 18); en el 55\% la capacidad para comprender la evolución y expectativas del mercado y entorno social, del producto/servicio y de los receptores de la comunicación y la identificación de tendencias emergentes (gráfico 17); en el 59\% para la capacidad de identificar los fundamentos de las relaciones públicas (gráfico 9) así como la capacidad para seleccionar el eje de comunicación y la creación del mensaje (gráfico 16); en el 60\% de los alumnos encuestados 
respecto a la adquisición de conocimientos suficientes sobre los orígenes históricos y la evolución de la disciplina (gráfico 1), la capacidad para analizar y comprender la naturaleza de los procesos estratégicos (gráfico 3) y para interpretar diferentes tipos de estrategias publicitarias y relacionales (gráfico 11).

Con un $66 \%$ nos encontramos la capacidad para identificar las diferentes variables intervinientes en el proceso estratégico de las organizaciones (gráfico 5); en el $67 \%$ de los casos la capacidad para identificar los fundamentos de la estrategia de la comunicación publicitaria (gráfico 8) así como para identificar los objetivos de comunicación, el sector de la audiencia a quien se dirige la comunicación o la formulación de la estrategia (gráfico 14); en el $70 \%$ de los estudiantes se observa la adquisición de competencias relativas al diseño del briefing y a la interpretación estratégica del contrabriefing (gráfico 13); en el 71\% la capacidad para identificar y aplicar las fases de la actuación estratégica (gráfico 4); en el 74\% la adquisición de conocimientos sobre el posicionamiento al servicio del marketing y de la publicidad (gráfico 12); $\mathrm{y}$, por último, con un $82 \%$ la adquisición de conocimientos sobre la conceptualización y reformulación de la Nueva Teoría Estratégica (gráfico 2), la capacidad de analizar objetivamente la realidad para extraer consideraciones válidas en el proceso estratégico (gráfico 6) y la capacidad para distinguir entre los conceptos de objetivo, estrategia, táctica y planificación (gráfico 3).

Los resultados del estudio nos muestran la orientación futura que debemos otorgar a este proceso didáctico, para reforzar los objetivos menos consolidados durante el curso académico 2012-2013. La investigación evaluativa se erige, por tanto, en una herramienta imprescindible que nos permite ofrecer a nuestros futuros estudiantes un proceso coherente con la adquisición de competencias, habilidades y destrezas en la planificación estratégica publicitaria y relacional

\section{Referencia bibliográfica}

GONZÁLEZ, J. y WAGENAAR, R. (2003). Tuning Educational Structures in Europe. Bilbao: Universidad de Deusto.

FANJUL, C. y GONZÁLEZ, C. (2010). "Nuevas metodologías docentes para el grado de Publicidad y Relaciones Públicas de la Universidad Jaume I de Castellón". En SIERRA, J. y SOTELO, J.(2010). Métodos de innovación docente aplicados a los estudios de Ciencias de la Comunicación. Madrid: Fragua. p. 318-332.

LASNIER, F. (2000): Réussir la formation par compétences. Montreal: Guérin.

Ley Orgánica 6/2001, de 21 de diciembre, de Universidades.

MINISTERIO DE EDUCACIÓN, CULTURA Y DEPORTE (2003): Documento marco para la integración del sistema universitario español en el EEES.

TARDIF, M. (2004): Los saberes del docente y su desarrollo profesional. Madrid: Ed. Narcea.

UNIVERSIDAD DE ALICANTE (2010). Memoria de Grado de Publicidad y Relaciones Públicas. 
ZABALZA, M. (2004): La enseñanza universitaria. El escenario y sus protagonistas. Madrid: Ed. Narcea..

\section{La autora}

Profesora Contratada Doctora del Dpto. de Comunicación y Psicología Social de la Universidad de Alicante. Licenciada en CC. de la Información por la U.C.M. Es Doctora en Sociología por la Universidad de Alicante y Premio BLAS INFANTE 2010, de Estudio e Investigación sobre Administración y Gestión Pública, concedido por el Instituto Andaluz de Administración Pública (IAAP) en su XIV edición. Ha desempeñado su actividad profesional en varias organizaciones públicas y privadas. Como PDI ha desarrollado, entre otras, líneas de investigación sobre la comunicación de proximidad de las entidades municipales y la agenda mediática local, que han sido publicadas en las actas de numerosos congresos y encuentros académicos, así como en revistas científicas. 